'ФГАОУ ВО «Российский университет дружбы народов»

117198, Российская

Федерация, Москва

ул. Миклухо-Маклая, 6

гГБУЗ г. Москвы

«Городская клиническая

больница им. А.К. Ерами-

шанцева Департамента

здравоохранения

г. Москвы»

129327, Российская

Федерация, Москва,

ул. Ленская, 15

ЗФГАОУ ВО «Первый

Московский государст-

венный медицинский

университет имени

И.М. Сеченова»

Минздрава России

(Сеченовский

Университет)

119991, Российская

Федерация, Москва,

ул. Трубецкая, 8, стр. 2

'Peoples' Friendship University of Russia (RUDN)

117198, Russian

Federation, Moscow,

Miklukho-Maklaya str., 6

${ }^{2}$ City Clinical Hospital

named after

A.K. Eramishantsev

2129327, Russian

Federation, Moscow,

Lenskaya str., 15

${ }^{3}$ I.M. Sechenov First

Moscow State Medical

University of the Ministry

of Health Care of Russian

Federation (Sechenov

University)

119991, Russian

Federation, Moscow,

Trubetskaya str., 8,

building 2

Контакты: Осипянц

Рита Александровна,

pchelka_maya.07@mail.ru

Contacts: Rita Osipyants, pchelka_maya.07@mail.ru

Поступила 24.04.2020

Принята 16.03.2021

Трудности генно-инженерной биологической терапии у пациента с активным ревматоидным артритом и вторичным амилоидозом с поражением почек (описание клинического случая)

\author{
Р.А. Осипянц ${ }^{1,2}$, М.3. Каневская ${ }^{2,3}$, Н.Л. Козловская ${ }^{1,2}$, К.А. Демьянова ${ }^{1,2}$, М.М. Саидова', \\ А.В. Беспалова², Т.Ш. Мирилашвили ${ }^{2}$
}

Представлено клиническое наблюдение пациента с активным ревматоидным артритом (РА), резистентным к стандартной базисной терапии, что послужило поводом для назначения ингибитора JAK (Janus kinase) тофацитиниба (Яквинус), а затем генно-инженерного биологического препарата (ГИБП), ингибитора рецепторов интерлейкина-6 (ИЛ-6) тоцилизумаба (Актемра). Данный клинический пример демонстрирует сочетание у одного пациента нескольких осложнений как самой болезни (амилоидной нефропатии с формированием нефротического синдрома (НС) в рамках вторичного АА-амилоидоза), так и базисной терапии (развитие коморбидных инфекций в виде госпитальной пневмонии и инфекционного артрита коленного сустава). Высказывается предположение о дополнительном вкладе НС в развитие инфекционных осложнений у пациентов с РА, получающих иммуносупрессивную терапию. Обсуждаются современные возможности лечения резистентного к терапии РА и целесообразность раннего назначения ГИБП до развития необратимых осложнений, а также возможные трудности терапии, обусловленные иммуносупрессией.

Подчеркивается важность профилактических мероприятий по иммунизации пневмококковой вакциной и необходимость коррекции нарушений системы гемостаза у пациентов с РА и НС.

Ключевые слова: ревматоидный артрит, АА-амилоидоз, генно-инженерные биологические препараты, коморбидные инфекции

Для цитирования: Осипянц РА, Каневская МЗ, Козловская НЛ, Демьянова КА, Саидова ММ, Беспалова АВ, Мирилашвили ТШ. Трудности генно-инженерной биологической терапии у пациента с активным ревматоидным артритом и вторичным амилоидозом с поражением почек (описание клинического случая). Научнопрактическая ревматология. 2021;59 (2): 225-228.

\title{
DIFFICULTIES OF BIOLOGICAL THERAPY IN THE PATIENT WITH ACTIVE RHEUMATOID ARTHRITIS AND SECONDARY RENAL AMYLOIDOSIS: A REPORT OF CLINICAL CASE
}

Rita A. Osipyants ${ }^{1,2,}$ Marina Z. Kanevskaya ${ }^{2,3}$, Natalia L. Kozlovskaya ${ }^{1,2}$, Kseniya A. Demyanova ${ }^{1,2,}$, Maryam M. Saidova ${ }^{1}$, Anna V. Bespalova ${ }^{2}$, Temuri Sh. Mirilashvili ${ }^{2}$

A clinical case of a patient with active rheumatoid arthritis (RA) resistant to standard basic therapy is presented, which served as the reason for the appointment of the target drug - Janus kinase, tofacitinib (Jaquinus) and then biological therapy using anti-IL6 receptor antibody tocilizumab (Actemra). This clinical example demonstrates the patient with the presence of several complications, both the course of the disease - amyloid nephropathy with the development of nephrotic syndrome (NS) as a manifestation of secondary amyloidosis with kidney damage, as well as basic therapy - the presence of comorbid infections with hospital pneumonia and infectious (septic) knee arthritis. An additional contribution of NS to the development of infectious complications in patients with RA receiving immunosuppressive therapy is supposed. Current treatment options for resistant RA and the feasibility of early use of biologics before the development of irreversible complications, as well as the difficulties of therapy and the complications associated with immunosuppression are discussed. Preventive measures for immunization with the antipneumococcal vaccine and the need to correct hemostatic disorders in patients with RA and NS are important. Key words: rheumatoid arthritis, AA-amyloidosis, biologics, comorbid infections

For citation: Osipyants RA, Kanevskaya MZ, Kozlovskaya NL, Demyanova KA, Saidova MM, Bespalova AV, Mirilashvili TSh. Difficulties of biological therapy in the patient with active rheumatoid arthritis and secondary renal amyloidosis: A report of clinical case. Nauchcno-Practicheskaya Revmatologia $=$ Rheumatology Science and Practice. 2021;59(2):225-228 (In Russ.).

Doi: 10.47360/1995-4484-2021-225-228

Ревматоидный артрит (РА) - иммуновоспалительное ревматическое заболевание (ИВРЗ), характеризующееся хроническим эрозивным артритом, системным поражением тканей и органов. Частота патологии почек у пациентов с РА варьирует от 57 до $73 \%$ [1, 2, 3]. Поражение почек при РА может быть обусловлено как самим заболеванием, так и лекарственными препаратами, применяюшимися для его лечения. Первая группа нефропатий включает гломерулярную патологию, развивающуюся либо как системное проявление РА, либо как его осложнение - гломерулонефриты (ГН) и амилоидоз соответственно. Вторая группа в большинстве случаев представлена поражением почечного интерстиция и канальцев, обусловленным применением нестероидных противовоспалительных препаратов (НПВП), 
включая тубуло-интерстициальный нефрит и острый канальцевый некроз. Наиболее распространенными видами почечной патологии у больных РА являются вторичный АА-амилоидоз и ГН [4]. У пациентов с РА причиной нефротического синдрома (НС), как правило, является АА-амилоидоз. Вторичный (реактивный) АА-амилоидоз серьезное жизнеугрожающее осложнение РА, обусловленное хроническим длительно текущим активным системным воспалительным процессом, характеризующееся повышением уровня сывороточного амилоидного белка A (SAA) и распространенным внеклеточным отложением нерастворимого фибриллярного гликопротеида - амилоида - в различных органах [5]. Контроль активности РА позволяет сдерживать выработку SAA, что является важным шагом в лечении амилоидоза. В то же время снижать уровень SAA при активном течении РA с помощью традиционных базисных противовоспалительных препаратов зачастую невозможно [6]. Раннее назначение генно-инженерных биологических препаратов (ГИБП) у больных РА с АAамилоидозом играет ключевую роль в снижении продукции SAA, предотвращении прогрессирования болезни и улучшении прогноза [7]. Ряд исследований демонстрируют высокую эффективность ингибиторов фактора некроза опухоли (ФНО) $\alpha$ и ингибитора ко-стимуляции Т-лимфоцитов (абатацепт) в терапии АА-амилоидоза $[8,9,10]$, однако достичь полной нормализации уровня SAA с их помощью удается не всегда. В свою очередь ингибитор рецепторов интерлейкина-6 (ИЛ-6) тоцилизумаб в большинстве случаев эффективно подавляет выработку острофазовых маркеров воспаления и SAA, а также способствует регрессу амилоидных депозитов, что приводит к уменьшению выраженности клинических симптомов АА-амилоидоза [6, 11]. Однако опыта его использования по этому показанию в нашей стране в настоящее время недостаточно.

Представляем клиническое наблюдение пациента К., 62 лет, инвалида 3-й группы, с ревматоидным артритом, у которого течение РА осложнилось развитием амилоидной нефропатии с формированием НС. Дебют РА - в 2013 г. (57 лет), появилась боль в коленных, плечевых, лучезапястных суставах и мелких суставах кистей. Выявлено умеренное повышение острофазовых маркеров воспаления (СОЭ - 35 мм/ч; С-реактивный белок (СРБ) 38 мг/л), ревматоидный фактор (РФ) - 310 МЕ/мл, антитела к циклическому цитруллинированному пептиду (АЦЦП) $>1000$ Ед./мл. Установлен диагноз РА, соответствующий критериям ACR/EULAR (2010), назначен метотрексат (MT) в дозе 10 мг/нед. подкожно (п/к) с повышением дозы до 25 мг/нед. в течение года. В 2016 г. в связи с сохранением активности РА к лечению добавлен метипред в дозе 4 мг/сут. С февраля 2018 г. отмечалось ухудшение состояния, сопровождавшееся снижением массы тела на 10 кг. С июня 2018 г. увеличена доза метипреда до 8 мг/сут., и к терапии добавлен сульфасалазин (СС3) в дозе 2000 мг/сут.

В июле 2018 г. произведена госпитализация в МКНЦ им. А. С. Логинова. Отмечалась высокая активность заболевания (6,7 по DAS-28); СОЭ - 80 мм/ч, СРБ - 170 мг/л, АЦЦП>1000 Ед./мл, общий анализ мочи (ОАМ) в норме. Проведена пульс-терапия метипредом по 500 мг № 3, далее получал метипред внутрь по 4-8 мг/сут.; МТ заменен на лефлуномид в дозе 20 мг/сут. Несмотря на это сохранялась высокая активность болезни. С начала декабря 2018 г. появились простудные явления, эпизоды повышения температуры тела до фебрильных цифр $\left(38-39{ }^{\circ} \mathrm{C}\right)$, проводилась антибактериальная терапия с эффектом. В ноябре 2018 г.: СОЭ - 80 мм/ч, гемоглобин - 96 г/л, СРБ - 49,3 мг/л, РФ - 398 МЕ/мл, ОАМ в норме. На основании отрицательного результата диаскин-теста и нормальной рентгенологической картины органов грудной клетки туберкулез исключен. Принимая во внимание высокую активность заболевания, недостаточную эффективность стандартной терапии БПВП, назначен ингибитор JAK (Janus kinase) тофацитиниб (ТОФА, Яквинус) в дозе 10 мг/сут. после предварительной вакцинации пневмококковой вакциной (Пневмо-23). Через 2 недели после вакцинации пациент отметил повышение температуры тела до $38{ }^{\circ} \mathrm{C}$, которая через несколько дней нормализовалась на фоне приема НПВП.

В феврале 2019 г. впервые был госпитализирован в ГКБ им. А. К. Ерамишанцева для выбора терапии. При поступлении состояние относительно удовлетворительное, положение активное, индекс массы тела (ИМТ) 19,0 кг $/$ м $^{2}$, температура $36,6^{\circ} \mathrm{C}$, артериальное давление (АД) 112/75 мм рт. ст. При осмотре: отмечена бледность кожных покровов, дефигурация суставов кистей и коленных суставов за счет пролиферативных изменений, пастозность стоп. По остальным органам и системам отклонений не выявлено. СРБ - 12 мг/л, СОЭ - 50 мм/ч, РФ - 461 МЕ/мл, гемоглобин - 106 г/л, железо - 2,2 мкмоль/л, общий белок 53 г/л, креатинин - 91 мкмоль/л, скорость клубочковой фильтрации (СКФ) - 77 мл/мин/м²; ОАМ: белок - 1 г/л, лейкоциты - 3-5 в поле зрения (п/зр.), эритроциты 0-1 в п/зр. 15.02.2019 начато лечение ТОФА в дозе 10 мг/сут. в комбинации с лефлуномидом в дозе 20 мг/сут. и метипредом в дозе 8 мг/сут. После первого приема ТОФА в стационаре через 48 ч появилась лихорадка до $38,8^{\circ} \mathrm{C}$, влажный кашель с трудноотделяемой светлой мокротой, одышка при нагрузке. При осмотре: число дыхательных движений (ЧДД) - 20/мин, сатурация кислородом капиллярной крови $\left(\mathrm{SaO}_{2}\right)-92 \%$, АД - 91/62 мм рт. ст., число сердечных сокращений (ЧСС) - 90/мин. Отмечался лейкоцитоз 11$15 \times 10^{9} /$ л, СОЭ - 50 мм/ч, СРБ - 214 мг/л, креатинин 165 мкмоль/л, СКФ - 37 мл/мин/1,73 м², прокальцитонин - 2 нг/мл (норма: <0,5 нг/мл), Д-димер - 1468 нг/мл (норма: <240 нг/мл). По данным мультиспиральной компьютерной томографии (МСКТ) органов грудной клетки (ОГК): картина двусторонней полисегментарной бронхопневмонии. Данных, свидетельствующих о тромбоэмболии легочной артерии (ТЭЛА), не получено. Диагностирована внутрибольничная двусторонняя пневмония, реактивная лимфаденопатия средостения. Назначена антибактериальная терапия (цефепим в дозе 4 г/сут., затем меронем в дозе 3 г + левофлоксацин в дозе 1 г/сут.). В связи с нарастанием дыхательной недостаточности пациент переведен в отделение реанимации и интенсивной терапии (ОРиТ), к лечению были добавлены антикоагулянтная (низкомолекулярный гепарин 6000 анти-Ха МЕ/0,6 мл подкожно) и инфузионная терапия. В ОРиТ состояние стабилизировалось: температура тела снизилась, регрессировали лабораторные маркеры воспаления, уменьшились кашель и одышка. На МСКТ ОГК: остаточные явления бронхопневмонии; острофазовые маркеры воспаления нормализовались (СОЭ - 15 мм/ч, СРБ - 4 мг/л). Однако обращали на себя внимание нарастающая гипопротеинемия (общий белок - 50 г/л, альбумин - 29 г/л), массивная протеинурия (суточная протеинурия $-6,18$ г/сут.), нарушение функции почек (креатинин - 198 мкмоль/л, 
СКФ - 29-30 мл/мин/1,73 м²). С целью уточнения характера поражения почек выполнена нефробиопсия. Результаты гистологического исследования биоптата почек: в препарате для световой микроскопии 22 клубочка, 1 из которых полностью склерозирован. Клубочки немного увеличены в размерах, в некоторых определяется небольшое расширение мезангия за счет отложения эозинофильных бесклеточных масс. Наблюдаются диффузно-очаговый фиброз интерстиция и атрофия канальцев, занимающие около 10-15\% площади паренхимы. В большинстве канальцев отмечается повреждение эпителия с диффузной утратой «щеточной каймы», ведущее к снижению его высоты и значительному расширению просвета канальцев. При окраске конго красным наблюдается позитивное окрашивание материала, инфильтрирующего клубочки. В поляризованном свете отмечается яблочно-зеленое свечение в проекции отложения бесклеточных масс. Заключение: Амилоидоз почки. Острый канальцевый некроз. С учетом вторичного амилоидоза, осложнившего активный РА, больному начато лечение тоцилизумабом (Актемра) в дозе 8 мг/кг в/в 1 раз в 4 нед. Через 2 недели (22.05.2019) после выписки из стационара появились выраженная припухлость и боль в левом коленном суставе, не купирующаяся обезболивающим препаратом, что не позволяло пациенту ходить самостоятельно; увеличились отеки нижних конечностей. При осмотре - состояние тяжелое, обращали на себя внимание транзиторная спутанность сознания, выраженный отек левой нижней конечности от верхней трети бедра до стопы, значимая дефигурация левого коленного сустава за счет экссудативных изменений. Осмотрен неврологом; для исключения острого нарушения мозгового кровообращения выполнена МСКТ головного мозга - патологии не обнаружено. Для уточнения диагноза проведена ультразвуковая допплерография (УЗДГ) нижних конечностей, не выявившая признаков тромбоза глубоких и поверхностных вен. Для исключения инфекционного (гнойного) артрита выполнена лечебно-диагностическая пункция левого коленного сустава: получено 5 мл вязкой желтой жидкости (гной). С диагнозом «инфекционный артрит левого коленного сустава» пациент госпитализирован в отделение гнойной хирургии. Проведены дренирование коленного сустава с использованием проточно-промывного метода и антибактериальная терапия в течение 2 недель. Ввиду длительной иммобилизации пациента рекомендована активная реабилитация с использованием ходунков и костылей на амбулаторном этапе. После выписки из стационара пациент находился на даче, передвигался при помощи инвалидного кресла. Вскоре родственники сообщили о его внезапной смерти. Аутопсия не проводилась. По всей вероятности, причиной летального исхода могла стать ТЭЛА.

Представленное клиническое наблюдение демонстрирует сочетание у одного пациента нескольких осложнений как самой болезни (формирование НС в рамках амилоидной нефропатии при АА-амилоидозе), так и терапии (развитие коморбидных инфекций в виде госпитальной пневмонии и гнойного артрита коленного сустава) и иллюстрирует сложности лечения в подобных случаях.

Согласно данным литературы, ведущее место среди причин АА-амилоидоза занимает РА, на долю которого приходится более $35 \%$ [12]. Почти 95\% пациентов с АА-амилоидозом имеют поражение почек, при этом терминальная почечная недостаточность на момент постановки диагноза выявляется в 10\% случаев [13]. Развитие вторичного
(АА) амилоидоза чаще наблюдается в первые 15 лет болезни, однако срок появления начальных признаков нефропатии зависит от активности РА: чем она выше, тем быстрее могут развиваться осложнения. Амилоидная нефропатия манифестирует минимальной протеинурией, которая, неуклонно нарастая, приводит к формированию НС с быстрым, в течение 1,5-2 лет, развитием почечной недостаточности. Если пациент до развития амилоидоза страдал артериальной гипертонией, как это часто бывает у лиц старшего возраста, то по мере прогрессирования нефропатии АД снижается, что нередко вызывает удивление врачей и недоверие к изложенным больным анамнестическим данным.

У нашего пациента период от дебюта РА до появления протеинурии составил 6 лет, что отражает высокую активность болезни и тяжесть течения артрита. Низкое АД, констатированное у больного во время всех госпитализаций, быстрое нарастание протеинурии с формированием НС после перенесённой пневмонии подтверждает закономерности течения амилоидной нефропатии. Сложнее обстоит дело с трактовкой нарушения функции почек, которое в данном случае может быть следствием как прогрессирования ренального амилоидоза, так и предшествующей терапии НПВП и антибиотиками, а также сочетания обеих причин, что подтверждено выявленным в нефробиоптате острым канальцевым некрозом, сочетающимся с отложением масс амилоида.

По данным Ү. Ocuda и соавт. [14], у пациентов с вторичным амилоидозом, большинство из которых составили больные РА, тоцилизумаб был более эффективен, чем и ингибиторы ФНО- $\alpha(p=0,007)$. Имеются данные о влиянии ТОФА на уровень SAA. Через 4 недели после начала терапии ТОФА + МТ наблюдались статистически значимое снижение уровня ИЛ-6 и нормализация содержания SAA у больных PA [15]. Однако требуются дальнейшие исследования эффективности тофацитиниба у пациентов с РА, осложненным АА- амилоидозом. Можно полагать, что раннее назначение ГИБП и ингибиторов JАК у больных активным РА с вторичным амилоидозом может способствовать эффективному подавлению продукции SAA и улучшению прогноза заболевания, а тоцилизумаб может быть препаратом выбора у этой категории пациентов.

В то же время терапия ГИБП, в том числе тоцилизумабом, и ингибиторами ЈАК сопряжена с повышенным риском развития серьезных инфекций различной локализации и реактивации латентной инфекции, в первую очередь туберкулеза [16, 17, 18]. Основными факторами риска развития инфекционных осложнений при лечении тоцилизумабом являются возраст старше 65 лет (относительный риск $(\mathrm{OP})=1,54 ; p=0,0415)$, длительность болезни более 10 лет $(\mathrm{OP}=1,8 ; p=0,0052)$, предшествующая или сопутствующая патология дыхательной системы $(\mathrm{OP}=1,9 ; p=0,002)$ и суточная доза глюкокортикоидов $>5$ мг $(\mathrm{OP}=2,8 ; p=0,0004)$ [19]. Пневмонии занимают лидирующее место в структуре инфекционных осложнений у пациентов с ИВРЗ [17]. У нашего больного назначение ТОФА также совпало с развитием госпитальной пневмонии. После лечения тяжелой респираторной инфекции развился НС как характерное клиническое проявление амилоидной нефропатии, хотя нельзя исключить, что НС сформировался раньше и мог быть еще одним фактором риска развития бронхолегочной инфекции. Применение тоцилизумаба сопровождалось возникновением инфекционного артрита коленного сустава. Не вызывает сомнений, 
что и в этом случае дополнительным фактором риска данного осложнения мог стать НС. Дальнейшее течение заболевания, завершившееся внезапной смертью пациента, позволяет предполагать, что ее причиной могла стать ТЭЛА. Последняя нередко осложняет НС, который ассоциирован с развитием венозных или, реже, артериальных тромбозов.

Представленный клинический пример демонстрирует, с одной стороны, современные возможности лечения резистентного к терапии РА и целесообразность раннего назначения ГИБП до развития необратимых осложнений, с другой - трудности терапии, обусловленные иммуносупрессией. Он также указывает на необходимость регулярного контроля нежелательных явлений и важность профилактических мероприятий.

\section{Л И Т Е А Т Р A / REFEREN CES}

1. Крель АА, Варшавский ВА, Каневская МЗ, Семейкина ОВ. Поражение почек у больных ревматоидным артритом. Терапевтический архив. 1990;(6):104-113. [Krel AA, Varshavskiy VA, Kanevskaya MZ, Semeykina OV. Kidney damage in patients with rheumatoid arthritis. Terapevticheskii arkhiv $=$ Therapeutic Archive. 1990;(6):104-113 (In Russ.)].

2. Чеботарева НВ, Гуляев СВ, Андросова ТВ, Милованова ЛЮ. Хроническая болезнь почек у больных ревматоидным артритом: частота, факторы риска, варианты поражения почек. Терапевтический архив. 2019;91(5):129-133. [Chebotareva NV, Guliaev SV, Androsova TV, Milivanova LYu. Chronic kidney disease in rheumatoid arthritis patients: Prevalence, risks factors, histopathological variants. Terapevticheskii arkhiv = Therapeutic Archive. 2019;91(5):129133 (In Russ.)]. doi: 10.26442/00403660.2019.05.000255

3. Kapoor T, Bathon J. Renal manifestations of rheumatoid arthritis Rheum Dis Clin North Am. 2018;44(4):571-584. doi: 10.1016/ j.rdc.2018.06.008

4. Helin H, Korpela M, Mstonen J, Pasternack AI. Renal biopsy findings and clinicopathologic correlations in rheumatoid arthritis. Arthritis Rheum. 1995;38(2):242-247. doi: 10.1002/art.1780380213

5. Mueller OS. Amyloidosis. Current rheumatology diagnosis and treatment; $2^{\text {nd }}$ ed. USA; McGraw Hill;2007.

6. Okuda Y. AA-amyloidosis - benefits and prospects of IL-6 inhibitors. Modern Rheum. 2019;29(2):268-274. doi: 10.1080/14397595.20 18.1515145

7. Sato H, Sakai T, Sugaya T, Otaki Y, Aoki K, Ishii K, et al. Tocilizumab dramatically ameliorated life-threatening diarrhea due to secondary amyloidosis associated with rheumatoid arthritis. Clin Rheumatol. 2009;28(9):1113-1116. doi: 10.1007/s10067-009-1185-0

8. Nakamura T, Higashi S, Tomoda K, Tsukano M, Shono M. Etanercept can induce resolution of renal deterioration in patients with amyloid A amyloidosis secondary to rheumatoid arthritis. Clin Rheumatol. 2010;29(12):1395-1401. doi: 10.1007/s10067-010-1469-4

9. Fernandez-Nebro A, Olive A, Castro MC, Varela AH, Riera E, Irigoyen MV, et al. Long-term TNF-alpha blockade in patients with amyloid A amyloidosis complicating rheumatic diseases. Am J Med. 2010;123(5):454-461. doi: 10.1016/j.amjmed.2009.11.010

10. Nakamura T, Kumon Y, Hirata S, Takaoka H. Abatacept may be effective and safe in patients with amyloid A amyloidosis secondary to rheumatoid arthritis. Clin Exp Rheumatol. 2014;32(4):501-508.

11. Vinicki J, De Rosa G, Laborder H. Renal amyloidosis secondary to rheumatoid arthritis: remission of proteinuria and renal function

\section{Конфликт интересов}

Все авторы заявляют об отсутствии потенциального конфликта интересов, требующего раскрытия, в данной статье.

\section{Прозрачность исследования}

Исследование не имело спонсорской поддержки. Авторы несут полную ответственность за предоставление окончательной версии рукописи в печать.

Декларация о финансовых и иных взаимоотношениях

Все авторы принимали участие в разработке концепции статьи и написании рукописи. Окончательная версия рукописи была одобрена всеми авторами. Авторы не получили гонорар за статью.

improvement with tocilizumab. J Clin Rheumatol. 2013;19(4):211213. doi: 10.1097/RHU.0b013e318293793c.

12. Саркисова ИА, Рамеев ВВ, Козловская ЛВ. Ревматоидный артрит как основная причина АА-амилоидоза. Клиническая геронтология. 2009;(2):14-20. [Sarkisova IA, Rameev VV, Kozlovskaya LV. Rheumatoid arthritis as the main cause of AA amyloidosis. Klinicheskaya gerontologiya = Clinical gerontology. 2009;2:14-20 (In Russ.)].

13. Kuroda T, Wada Y, Nakano M. Diagnosis and treatment of AA-amyloidosis with rheumatoid arthritis: state of the art. Amyloidosis. 2013:187-212. doi: 10.5772/54332

14. Okuda Y, Ymada T, Ueda M, Ando Y. First nationwide survey of 199 patients with amyloid A amyloidosis in Japan. Intern Med. 2018;57(23):3351-3355. doi: 10.2169/internalmedicine

15. Migita K, Izumi Y, Jiuchi Y, Kozuru H, Kawahara C, Izumi M, et al. Effect of Janus kinase inhibitor tofacitinib on circulating serum amyloid A and interleukin-6 during treatment for rheumatoid arthritis. Clin Exp Immunol. 2014;175(2):208-214. doi: 10.1111/ cei.12234.

16. Белов БС. Терапия генно-инженерными биологическими препаратами и инфекции у больных ревматоидным артритом: актуальность и перспективы. Научно-практическая ревматология. 2014;52(3):322-330. [Belov BS. Biological therapy and infections in patients with rheumatoid arthritis: Relevance and prospects. Nauchno-prakticheskaya revmatologiya $=$ Rheumatology Science and Practice. 2014;52(3):322-330 (In Russ.)]. doi: 10.14412/1995-4484-2014-322-330

17. Белов БС, Тарасова ГМ, Буханова ДВ. Коморбидные инфекции при ревматических заболеваниях. Антибиотики и химиотерапия. 2019;64:1-2. [Belov BS, Tarasova GM, Bukhanova DV. Comorbid infections in rheumatic diseases. Antibiotiki i khimioterapiya $=$ Antibiotics and Chemotherapy. 2019;64:1-2 (In Russ.)]. doi: 10.24411/0235W2990W2019W10009

18. Campbell L, Chen C, Bhagat SS, Parker RA, Östör AJ. Risk of adverse events including serious infections in rheumatoid arthritis patients treated with tocilizumab: a systematic literature review and meta-analysis of randomized controlled trials. Rheumatology (Oxford). 2011;50(3):552-62. doi: 10.1093/rheumatology/keq343.

19. Koike T, Harigai M, Inokuma S, Ishiguro N, Ryu J, Takeuchi T, et al. Effectiveness and safety of tocilizumab: postmarketing surveillance of 7901 patients with rheumatoid arthritis in Japan. J Rheumatol. 2014;41(1):15-23. doi: 10.3899/jrheum.130466
Осипянц P.A. ORCID: https://orcid.org/0000-0003-3485-8817

Каневская M.3. ORCID: https://orcid.org/0000-0001-9935-2126

Козловская Н.Л. ORCID: https://orcid.org/0000-0002-4275-0315

Демьянова K.A. ORCID: https://orcid.org/0000-0001-8927-5841

Саидова M.M. ORCID: https://orcid.org/0000-0001-7233-3013

Беспалова A.B. ORCID: https://orcid.org/0000-0001-7324-8849

Мирилашвили Т.Ш. ORCID: https://orcid.org/0000-0003-4219-8548 